\title{
Perancangan dan Pembuatan Business Logic Layer Pada Situs Social Networking Berbasis Penelitian (KoKKo)
}

\author{
Cahya Damarjati, Lukito Edi Nugroho, Sri Suning Kusumawardani \\ Fakultas Sains dan Teknologi, Universitas Teknologi Yogyakarta \\ Jl. Ringroad Utara. Jombor, Sleman, Yogyakarta, Indonesia \\ Email: cahya.damarjati@yahoo.com
}

\begin{abstract}
Business Logic Layer on Social Networking Sites Design and Development Based on Research. KoKKo, virtual community for science was born based on the belief that "no one knows everything, and everyone knows something" atau "none of us is as smart as all of us". KoKKo is a web application that use three tier web architecture. The three tier of KoKKo are presentation layer, BLL, and DAL. This final prject will discuss everything about engineering and implementation of BLL in KoKKo Web Application. BLL implement object oriented programming concept. With that concept, BLL consists of methods definition that is packaged in class. BLL methods contain DAL functions to access database. Presentation layer use BLL methods to pick data, add data, change date, or delete data from database.
\end{abstract}

Keyword: Three tier web architecture, BLL, Object Oriented Programming, Class, Methods.

\begin{abstract}
Abstrak. KoKKo sebagai komunitas virtual untuk berbagi pengetahuan, lahir dari adanya istilah "no one knows everything, and everyone knows something" atau "none of us is as smart as all of us". Wujud KoKKo berupa aplikasi web yang menggunakan Arsitektur Web Tiga Tingkat. Tiga Tingkat dari KoKKo adalah tingkat presentasi, BLL, dan DAL. Penelitian ini akan membahas segala hal tentang perancangan dan implementasi BLL pada aplikasi web KoKKo. BLL menerapkan konsep Pemrograman Berorientasi Objek (OOP). Dengan konsep tersebut, BLL tersusun dari definisi Metode-Metode yang dikemas dalam Kelas. Metode BLL berisi fungsi-fungsi DAL untuk mengakses basis data. Tingkat presentasi menggunakan metode BLL untuk mengambil data, menambah data, mengubah data, atau menghapus data dari basis data.
\end{abstract}

Kata kunci: Arsitektur Web Tiga Tingkat, BLL, Pemrograman Beorientasi Objek, Kelas, Metode.

\section{Pendahuluan}

\subsection{Latar Belakang}

Laboratorium adalah tempat seorang peneliti menghabiskan waktunya mengerjakan penelitiannya atau tempat seorang praktikan melakukan praktikum atau percobaan. Laboratorium menyediakan semua keperluannya dalam perancangan, pembuatan dan pelaporan hasil penelitiannya. Oleh karena itu, sebuah laboratorium harus mempunyai peralatan dan perlengkapan yang cukup agar dapat mendukung kondisi tersebut. Laboratorium harus mempunyai papan tulis, atau media untuk mencatat hal-hal yang perlu dicatat oleh orang yang berada di laboratorium tersebut. Selain itu, laboratorium juga harus mempunyai media seperti kalender, agenda kegiatan untuk membantu peneliti dalam merancang kegiatannya di tempat 
kerjanya. Agar Laboratorium tidak membosankan atau bahkan meningkatkan kinerja pemiliknya, dibutuhkan penampilan dan hiasan yang menarik di setiap bagian Laboratorium. Laboratorium mempunyai ruangan pribadi, dan ruangan yang bisa dikunjungi oleh tamutamunya. Laboratorium juga membutuhkan lemari atau rak yang digunakan untuk menyimpan semua dokumen yang berguna bagi peneliti dalam bekerja. Peneliti tidak harus selalu menghabiskan waktu di laboratoriumnya. Dia juga harus selalu memelihara komunikasi dengan dunia luar selain untuk menjaga status sosialnya, peneliti juga bisa mendapatkan berita - berita terbaru tentang ilmu pengetahuan atau keadaan temannya. Seorang peneliti bisa mendapatkan semua informasi yang dibutuhkannya di kampus, perpustakaan, atau bahkan di laboratorium temannya.

Di jaman dengan teknologi yang maju sekarang ini teknologi web memegang peranan penting dalam pertukaran informasi. Sampai saat ini, teknologi web sudah dimanfatkan dalam berbagai hal. Selain untuk menyampaikan profil si pembuatnya, web dimanfaatkan sebagai media forum untuk bertukar pikiran, jual beli barang, penyimpanan berkas dengan berbagai bentuk format berkas, dan masih banyak lagi yang bisa dimanfaatkan oleh teknologi ini. Selain yang sudah disebutkan sebelumnya, teknologi web yang baru yaitu web 2.0 juga dapat dimanfaatkan untuk membuat suatu komunitas virtual. komunitas tersebut menyediakan fasilitas yang dapat digunakan oleh pengguna atau anggotanya. Fitur-fitur tersebut dibuat untuk menarik banyak user menjadi anggotanya dan mempertahankan anggota yang sudah ada agar kerasan memanfaatkan komunitas tersebut. Web komunitas yang sudah ada contohnya adalah facebook, friendster, akucintasekolah, dll. Umumnya web-web tersebut dijadikan sebagai perantara anggotanya untuk mencari teman baru dan mempererat hubungan tali persaudaraan. Dengan adanya teknologi Web 2.0, laboratorium, kampus, dll tidak harus berbentuk nyata, tetapi juga bisa berupa bentuk virtual. Web 2.0 dapat dimanfaatkan untuk membuat software yang dapat dimanfaatkan oleh para peneliti. Software yang akan dibuat berupa web komunitas untuk para peneliti yang fiturnya bisa berupa laboratorium atau kampus beserta kelengkapannya dalam bentuk virtual dan fitur yang memudahkan peneliti dalam berinteraksi dengan peneliti lain dalam berbagi informasi.

Pengembangan web untuk komunitas para peneliti ini menggunakan arsitektur tiga tingkat. Tiga tingkatan itu adalah tingkat User Interface atau Presentasi, BLL, dan DAL. Tujuannya adalah agar memudahkan pengembangan selanjutnya.

\subsection{Perumusan Masalah}

Berdasarkan latar belakang masalah yang telah dijelaskan pada sub bab sebelumnya, dibuat rumusan masalah sebagai berikut: (1) Bagaimana membuat perangkat lunak yang dapat mewakili model aktifitas para peneliti dengan arsitektur tiga tingkat. (2) Bagaimana mengimplementasikan teknologi .NET untuk mengembangkan web Kokko (Komunitas untuk Kecerdasan Kolektif). (3) Bagaimana membuat tingkat BLL dalam pengembangan web Kokko menggunakan teknologi .NET.

\subsection{Batasan Masalah}

Batasan masalah terhadap perangkat lunak yang akan dibuat adalah sebagai berikut: (1) Tampilan aplikasi ke pengguna menggunakan bahasa Inggris. (2) Aplikasi yang akan dikembangkan mempunyai fitur untuk upload dan download berkas dari document server beserta pengaturan berkas hasil upload. (3) Aplikasi ini mempunyai fitur kalender dan fitur untuk mengatur jadwal kegiatan pengguna. (4) Aplikasi ini mempunyai fitur untuk mengelola komunitas, yaitu melihat profil teman, menambah teman dan menghapus teman. (5) Aplikasi ini mempunyai fitur untuk melihat dan mengirim pesan antar anggota. (6) Aplikasi ini mempunyai fitur untuk pembuatan blog dan komentar blog yang sederhana beserta pengaturannya. 


\subsection{Maksud dan Tujuan}

Tujuan dari penelitian yang akan dilakukan adalah: (1) Untuk mengembangkan Business Logic Layer (BLL) dalam aplikasi web komunitas untuk kecerdasan kolektif (KoKKo). (2) Membuat BLL yang dapat menjembatani komunikasi antara tingkat presentasi dengan tingkat DAL dengan teknologi .NET.

\section{Tinjauan Pustaka}

\subsection{Definisi Kokko}

Kepanjangan dari Kokko adalah komunitas untuk kecerdasan kolektif. Kokko merupakan komunitas virtual umum untuk penggunanya yang terlibat dalam manajemen sains khususnya dalam riset atau penelitian (Tugas akhir, Skripsi, Thesis, atau penelitian tertentu). Kokko menyediakan sarana yang dapat membantu kelancaran penelitian seperti sarana untuk berbagi resource, pengaturan jadwal kegiatan dan komunikasi antar pengguna. Kokko adalah wujud dari aplikasi yang memakai teknologi web 2.0 dalam melaksanakan tujuannya. Sifat-sifat Kokko adalah sebagai berikut: (1) Openness: kokko bersifat terbuka, setiap orang dapat mendaftar di web ini. (2) Peering: adanya form -form untuk mengambil dan menampilkan informasi dan resources. (3) Sharing: Kokko mendukung resource yang bermanfaat untuk disimpan atau dibagi ke pengguna lain dalam risetnya. (4) Global reach $\rightarrow$ kokko menggunakan bahasa internasional yaitu bahasa inggris, sehingga kokko bisa dipakai oleh banyak pengguna di berbagai Negara.

Lahirnya Kokko dilatarbelakangi dengan adanya istilah "no one knows everything, and everyone knows something" atau "none of us is as smart as all of us". Kedua pernyataan tersebut memunculkan ide untuk membuat wahana untuk kecerdasan bersama yang bermanfaat untuk semua. Tujuan dari dibuatnya Kokko adalah sebagai berikut: (1) Sebagai asisten penggunanya dalam melaksanakan aktifitasnya, khususnya dalam penanganan penelitian. (2) Menyediakan sarana untuk perkembangan ilmu seperti interaksi antar pengguna dan diskusi pada topik pembicaraan tertentu. (3) Mendokumentasikan ilmu dan resources yang didapatkan dari penelitiannya.

Kokko bersifat user-centered. Artinya penggunalah yang menjadi subjek dalam lingkungan Kokko. Sebagai subjek, pengguna dapat melakukan berbagai aktifitas sebagai berikut: (1) Mengajukan pertanyaan kepada pengguna lain. (2) Menjawab pertanyaan yang diajukan pengguna lain. (3) Memposting resources (blog, dokumen, dll). (4) Mengatur resources hasil posting. (5) Berkomunikasi dengan pengguna lain dengan mode yang berbedabeda: one-to-one, many-to-one, many-to-many. (6) Mengatur jadwal kegiatan harian pribadi, atau kegiatan penelitian.

\subsection{Business Logic Layer}

Tingkat ini pada dasarnya hanya membuat kelas-kelas yang memanggil metode-metode dari DAL (Data Access Layer). DAL membuat kelas dan metode yang berfungsi untuk berkomunikasi dengan database secara langsung. Tujuan dibuatnya BLL adalah agar ASP.NET lebih mudah berkomunikasi dengan basis data dan seperti layaknya konsep OOP pemanggilan metode kelas BLL dapat dilakukan berulang-ulang. Tujuan lain dari dibuatnya BLL adalah mencegah tingkat presentasi mengakses secara langsung basis data sehingga keamanan data menjadi terancam.

Dalam implementasinya, BLL mendefinisikan kelas-kelas, metode-metode di dalam kelas dan menjalankan fungsi-fungsi di dalam metode tersebut. Fungsi-fungsi tersebut bertujuan untuk memanipulasi data hasil pemanggilan metode dari DAL untuk ditampilkan di layer presentasi atau sebaliknya, BLL menerima data dari tingkat presentasi dan memanipulasinya untuk dikirimkan ke basis data melalui metode DAL. Format pembuatan BLL secara umum dengan VB.NET adalah sebagai berikut: 


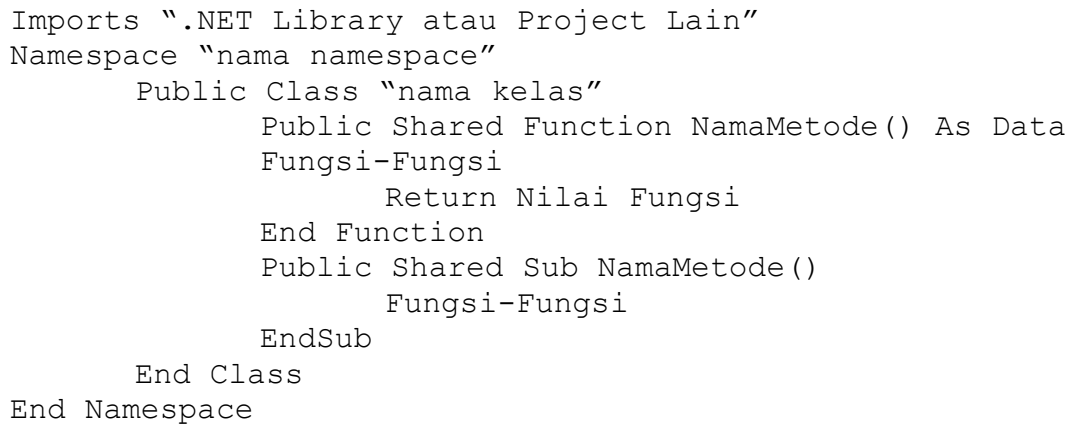

\section{Metodologi Penelitian}

\subsection{Analisis Sistem}

Kokko sebagai komunitas virtual yang dikhususkan dalam pengembangan ilmu dan penelitian yang telah dijelaskan secara rinci di bab dua dapat diwujudkan dengan pemakaian teknologi yang sudah ada. Dari fitur-fitur Kokko yang telah diuraikan di bab dua maka dirancang aplikasi berbasis web Kokko yang terbagi menjadi lima bagian. Kelima bagian tersebut dapat dilihat pada tabel 1 .

Tabel 1. Tabel Pembagian Aplikasi Kokko

\begin{tabular}{lll}
\hline No. & \multicolumn{1}{c}{ Nama } & \multicolumn{2}{c}{ Keterangan } \\
\hline 1. & Blog & $\begin{array}{l}\text { Digunakan oleh penggunanya untuk membuat tulisan yang dapat } \\
\text { dikomentari oleh pengguna lain. }\end{array}$ \\
\hline 2. & Manajemen Teman & $\begin{array}{l}\text { Tujuannya untuk pengaturan teman seperti menambah teman, melihat profil } \\
\text { teman, dan menghapus teman. }\end{array}$ \\
\hline 3. & Laboratorium & Merupakan ruang kerja pengguna yang mempunyai banyak fasilitas. \\
\hline 4. & Penelitian & $\begin{array}{l}\text { Semua penelitian yang sedang dikerjakan oleh anggota dikerjakan di bagian } \\
\text { ini. }\end{array}$ \\
\hline 5. & Pesan & merupakan sarana untuk berkomunikasi antar teman. \\
\hline
\end{tabular}

Tabel 2. Fitur-Fitur Kokko

\begin{tabular}{lll}
\hline No. & Bagian Kokko & \\
\hline 1. & Blog & Membuat Blog baru \\
& & Menghapus Blog \\
& & Membuat komentar terhadap blog \\
\hline $2 . \quad$ Manajemen Teman & Melihat profil teman \\
& & Menambah teman \\
& & Menghapus teman \\
& & Menerima atau menolak ajakan jadi teman \\
\hline 3. & Laboratorium & Mengatur jadwal kegiatan sehari-hari \\
& & Melihat dan mengubah profil \\
& & Melihat daftar dan jadwal penelitian yang sedang dilakukan \\
\hline 4. & Penelitian & Membuat Penelitian \\
& & Mengajak teman untuk bergabung dalam penelitian atau mengeluarkan \\
& & teman dari penelitian \\
& & Meng-upload dan download berkas \\
& & Membuat daftar to-do-list \\
& & Membuat log book \\
& & Mengelola jadwal penelitian \\
\hline 5. & Pesan & Mengirim pesan ke teman \\
& & Membaca pesan yang dikirim \\
& & Membaca pesan yang diterima \\
& Menghapus pesan \\
\hline & &
\end{tabular}


Setiap bagian mempunyai fitur fitur yang menarik. Fitur-fitur tersebut dapat mewujudkan tujuan dari dibuatnya aplikasi web Kokko. Fitur-fitur dari setiap bagian Kokko yang akan dibuat dapat dilihat pada tabel 2.

\subsection{Analisis Kebutuhan}

Kokko merupakan perangkat lunak yang dikembangkan untuk membantu pengelolaan komunitas dan penelitian secara online. Kokko bisa diakses dengan komputer yang mempunyai akses internet dan mempunyai web browser yang terpasang di sistem operasi komputer tersebut. Pembuatan aplikasi Kokko melibatkan sebagian besar teknologi .NET.

\subsection{Perancangan Aplikasi}

Pembuatan aplikasi web Kokko dilakukan dengan mengimplementasikan kelima bagian Kokko ke dalam pemrograman. Akan tetapi, sebelum pemrograman dilakukan diperlukan adanya perancangan Usecase Diagram, Collaboration Diagram, dan Sequence Diagram. Tujuannya adalah agar arah pembuatan web itu jelas, dan pemrograman menjadi lebih mudah. Secara urut, tahap-tahap yang dilakukan dalam perancangan aplikasi web Kokko adalah sebagai berikut: (1) Menentukan spesifikasi minimal aplikasi. (2) Merancang diagram use case, dan sequence. (3) Pembuatan kelas dan metode BLL sesuai perancangan. (4) Pemakaian metode BLL untuk aplikasi tingkat presentasi. (5) Pengujian dan evaluasi aplikasi di tingkat presentasi.

\subsection{Diagram Use Case}

Diagram use case untuk aplikasi web Kokko dapat dilihat pada gambar 1. Diagram ini menunjukkan segala aktivitas yang dapat dilakukan oleh seorang pengguna dengan aplikasi ini. Dari use case, pengguna dapat mengelola blog, teman, penelitian, laboratorium dan pesan. Semua aktivitas dapat dilakukan dengan syarat pengguna telah melakukan login menjadi anggota Kokko.

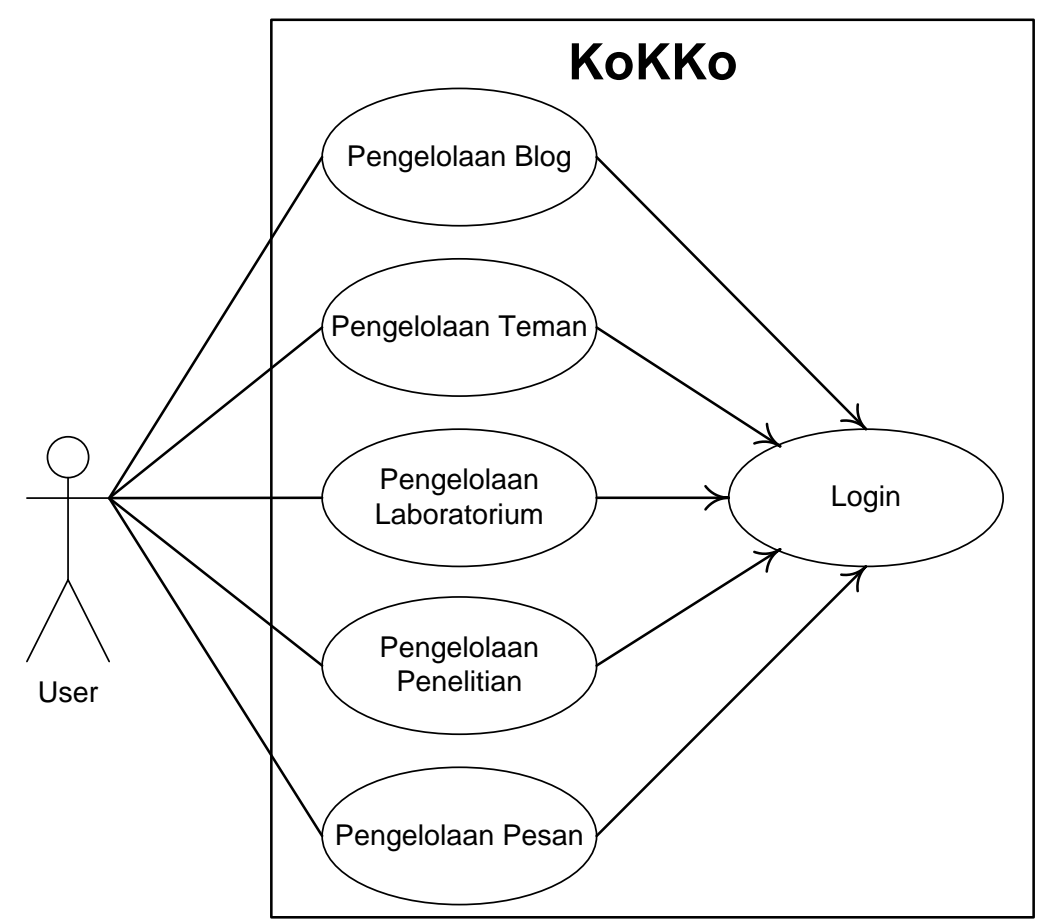

Gambar 1. Diagram Use Case 


\subsection{Analisis Arsitektur}

Arsitektur web tiga tingkat digunakan dalam pembuatan aplikasi Kokko. Tiga tingkatan itu adalah Presentasi, BLL dan DAL. Tingkat presentasi merupakan tingkatan yang paling dekat dengan pengguna. Tingkat ini tugasnya adalah menampilkan data untuk pengguna dan memanggil fungsi yang ada pada tingkatan dibawahnya tingkat BLL. Pembuatan aplikasi Kokko di tingkat ini menggunakan ASP.NET dengan C\# dan VB.NET sebagai kode yang terpasang di setiap halaman ASP.NET.

Tingkat kedua adalah BLL tingkat ini menggunakan bahasa pemrograman VB.NET. keuntungan memakai teknologi .NET adalah bahasa pemrograman yang mendukung teknologi ini dapat saling berkomunikasi. Oleh karena itu meskipun di tingkat presentasi bahasa yang digunakan adalah $\mathrm{C \#}$, hal itu tidak menjadi masalah lagi. Kedua tingkat presentasi dan BLL dapat berkomunikasi dengan lancar. Kode BLL semua akan dibuat di folder App_Code dari aplikasi web ASP.NET

Tingkat ketiga adalah DAL. Tingkat ini menggunakan bahasa C\# dalam pembuatannya. DAL berhubungan langsung dengan basis data. DAL membuat kelas dan fungsi untuk memudahkan pengaksesan tabel dalam basis data seperti fungsi, select, create, update, dan delete. DAL juga membuat fungsi untuk pengaksesan store procedure yang ada di basis data.

\section{Pengujian dan Pembahasan}

\subsection{Implementasi Sistem}

Pada bab sebelumnya, perencanaan Kokko meliputi lima bagian utama. Kelima bagian itu adalah blog, teman, penelitian, laboratorium, dan pesan. Dari perencanaan pada bab tiga maka dibuatlah aplikasi web Kokko dengan menerapkan arsitektur tiga tingkat. Pengkodean dilakukan dengan visual studio 2008. Pengkodean seluruhnya menggunakan bahasa pemrograman C\# dan VB.NET, dan bahasa pemrograman web ASP.NET. Pemrograman juga menggunakan library ajax yang dapat digunakan dalam visual studio. Pembuatan aplikasi dilakukan dengan menggunakan framework dari Microsoft Innovation Center UGM bernama Cwek. Dalam penelitian ini framework Cwek dikembangkan dan dibangun menjadi aplikasi Kokko. Kelas dan metode yang tidak dipakai dalam Kokko di keluarkan dari program. Tingkat kedua dari arsitektur tiga tingkat adalah BLL, pembuatan BLL pada visual studio 2008 disimpan di folder App_Code.

\subsection{Kelas BLL dan Metodenya}

Kelas yang dipakai dalam aplikasi Kokko sebagai BLL adalah: (1) Blogs: merupakan kelas BLL yang dibuat dengan tujuan untuk mengelola bagian blog Kokko. (2) Friends: merupakan kelas BLL yang dibuat dengan tujuan untuk mengelola bagian teman Kokko. (3) Members: merupakan kelas BLL yang dibuat dengan tujuan untuk mengelola bagian pengguna Kokko. (4) Message: merupakan kelas BLL yang dibuat dengan tujuan untuk mengelola bagian pesan Kokko. (5) Research: merupakan kelas BLL yang dibuat dengan tujuan untuk mengelola bagian penelitian Kokko. (6) DataGenerator: kelas yang berisi metode untuk mengambil data jadwal kegiatan. Metode yang digunakan adalah GetData dan data yang diambil bertipe dataset. DataGenerator di aplikasi Kokko ada tiga kelas. DataGenerator pertama adalah kelas untuk mengambil data jadwal kegiatan sehari-hari pengguna. Kelas ini mengakses basis data tabel KokkoSchedulerCalendar. DataGenerator kedua adalah kelas untuk mengambil data jadwal kegiatan suatu penelitian. Kelas ini mengakses basis data tabel KokkoResearchCalendar. DataGenerator ketiga adalah kelas untuk mengambil data jadwal kegiatan kumpulan penelitian seorang pengguna. Kelas ini mengakses basis data tabel KokkoResearchCalendar dan KokkoResearchUser. 


\subsection{Pengujian BLL}

Pada sub bab pengujian ini, hanya akan dijelaskan pengujian untuk metode-metode tertentu yang dapat mewakili seluruh pengujian metode BLL. Pengujian pertama akan dilakukan pada halaman untuk mengelola anggota penelitian. Tampilan halaman dapat dilihat di gambar 2 .

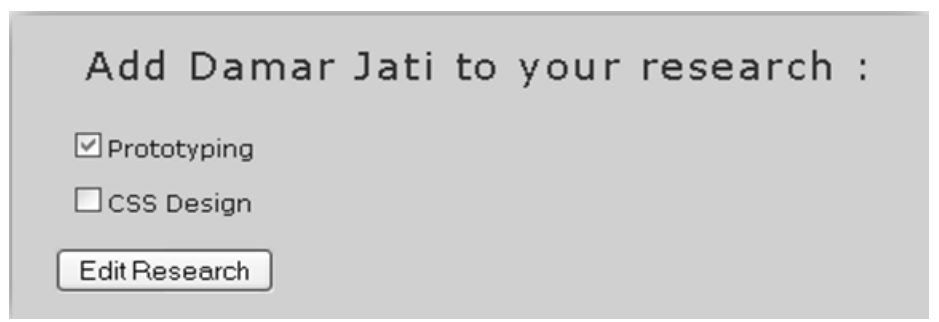

Gambar 2. Halaman Pengelolaan Anggota Penelitian

Kode 1. Kode Aksi Pengelolaan Anggota Penelitian

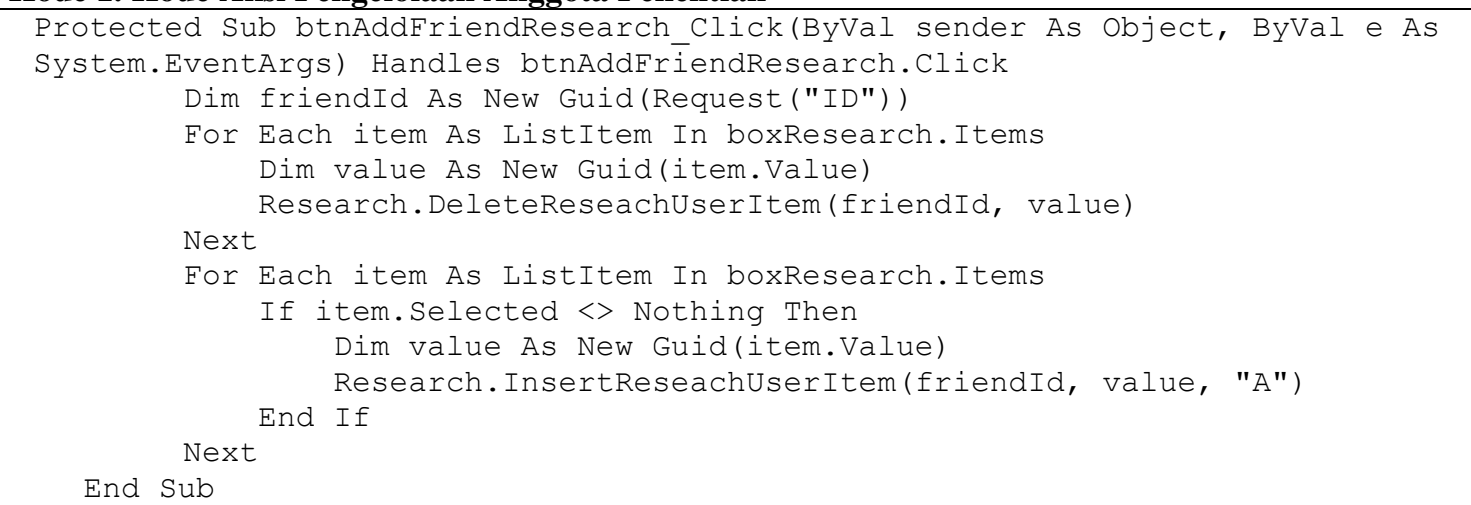

Kode aksi btnAddFriendResearch_Click dijalankan saat tombol EditResearch ditekan. Metode ini berisi fungsi untuk memanggi metode BLL DeleteResearchUserItem dan InsertResearchUserItem dari kelas Research. Kedua metode ini digunakan untuk mengubah data pada basis data tabel KokkoResearchUser. Metode DeleteResearchUserItem dijalankan untuk menghapus baris data tertentu pada tabel KokkoResearchUser, sedangkan metode InsertResearchUser digunakan untuk menambah baris data baru pada tabel KokkoResearchUser. Pada saat pemrograman, pengujian ini berhasil dilakukan untuk mengubah nilai check pada checkbox ditandai dengan adanya pilihan yang di-check sebagai dampak dari operasi sebelumnya.

Pengujian pada halaman untuk mengelola anggota penelitian telah mewakili pengujian metode-metode BLL yang mempunyai sifat Select, Insert dan Delete. Pengujian yang kedua adalah pengujian untuk update. Pengujian ini dapat dilakukan di halaman pengaturan profil pengguna. Gambar 3 menampilkan halaman pengaturan profil tersebut.

\begin{tabular}{|l|l|}
\hline Name & Nohan Bhadrika \\
Status & Student \\
College & Ptudent \\
Angkatan & Researcher \\
& Public \\
Major & Electrical Engineering \\
Location & Yogyakarta \\
\hline
\end{tabular}

Gambar 3. Halaman Pengaturan Profil Pengguna 
Kode 2. Kode Aksi Pengaturan Profil Pengguna

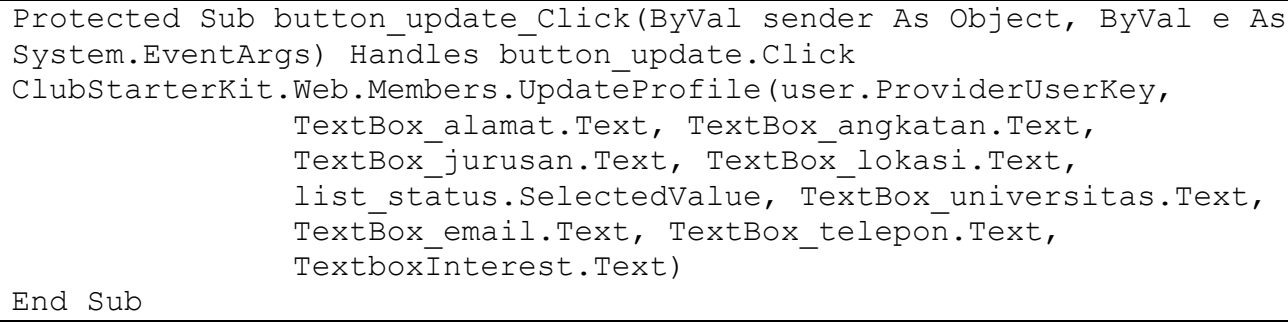

Kode 2 memanggil metode BLL UpdateProfile dari kelas Members. Metode ini bertujuan untuk meng-update baris data tertentu pada tabel KokkoProfile. Metode secara keseluruhan mengubah data alamat, angkatan, jurusan, lokasi, status, universitas, email, telepon, dan interest. Pengujian update data ini berhasil diujikan dinyatakan dengan perubahan data di basis data atau data halaman profil pengguna yang ditampilkan sesuai dengan update terakhir. Pengujian update ini mewakili pengujian untuk metode-metode update lain yang umumnya mempunyai fungsi-fungsi yang hampir sama.

\subsection{Evaluasi Aplikasi}

Secara umum aplikasi Kokko di semua tingkat telah memenuhi syarat minimal yang diharapkan dan semua kelas, metode dan fungsi dapat bekerja sesuai harapan, terbukti dengan berhasilnya pengujian sebagian dari aplikasi Kokko yang mewakili keseluruhan Kelas dan Metode. Selain itu, pengembangan juga lebih mudah dilakukan karena aplikasi Kokko menerapkan arsitektur web tiga tingkat.

\subsubsection{Kelebihan BLL Yang Telah Dibuat}

BLL yang telah dibuat selama ini telah menjalankan fungsinya dengan baik. BLL dapat menghubungkan komunikasi yang dilakukan antara tingkat presentasi dengan basis data. Metode-metode BLL dikelompokkan sesuai kegunaannnya. Misalnya metode untuk membuat pesan diletakkan di BLL kelas Message. Oleh karena itu, pengembangan aplikasi jadi lebih mudah. Penamaan masing-masing variabel, metode dan kelas BLL disesuaikan dengan perannya.

\subsubsection{Kelemahan BLL Yang Telah Dibuat}

Secara biasa BLL dapat menjalankan perannya dengan baik, untuk kondisi yang tidak biasa, mungkin saja komunikasi antara presentasi dengan basis data bisa terganggu karena kurangnya validasi data yang keluar masuk BLL.

\subsubsection{Pengembangan Aplikasi}

Dengan dibaginya aplikasi dalam tiga tingkat dan pembagian aplikasi Kokko menjadi lima bagian maka pengembangan lebih mudah dilakukan. Aplikasi Kokko menggunakan teknologi .NET dan pemrograman menggunakan visual studio 2008. Oleh karena itu, disarankan pengembangan dilakukan dengan tool yang sama atau dengan versi yang terbaru.

\section{Kesimpulan}

Kesimpulan yang dapat diambil dalam penelitian ini dengan mengacu pada bab-bab sebelumnya: (1) Aplikasi Kokko menerapkan arsitektur tiga tingkat. Tingkat presentasi, tingkat BLL (Business Logic Layer), dan tingkat DAL (Data Access Layer). (2) Aplikasi Kokko 
menggunakan teknologi .NET. Bahasa pemrograman web menggunakan ASP.NET, dan bahasa pemrograman menggunakan C\#, dan VB.NET. (3) Tingkat BLL dari aplikasi Kokko menggunakan bahasa pemrograman VB.NET. (4) BLL dapat bekerja dengan baik dalam memainkan perannya, dengan menyediakan kelas dan metode untuk mengakses tingkat DAL yang dapat digunakan di tingkat presentasi.

\section{Saran}

Penulis ingin memberikan beberapa saran yang mungkin dapat membantu dalam pengembangan aplikasi ini yaitu: (1) Untuk pengembangan aplikasi web Kokko, diperlukan adanya penambahan validasi untuk data-data tertentu di metode-metode BLL. (2) Pengembangan aplikasi sebaiknya menggunakan visual studio 2008 agar pengembangan dapat dilakukan dengan lebih mudah. (3) Penambahan komentar sebagai penjelasan metode juga diperlukan untuk pengembangan aplikasi Kokko.

\section{Referensi}

Conery, R. 2009. "Query SubSonic 2.1", (Online), (http://subsonicproject.com/querying/, diakses 11 Februari 2009).

Kuhl, S. 2006. "Getting Started With SubSonic", (Online), (http://cid-b11213b176cf5d39. skydrive.live.com/self.aspx/Public/SubSonic.zip), diakses 11 Februari 2009.

Lee, W.M. 2005. "Visual Basic 2005 JumpStart". California: O'Reilly.

MacDonald, M. 2007. "Beginning ASP.NET 3.5 in C\# 2008 From Novice To Profesional”. New York: Apress.

Microsoft. 2008. "MSDN Library for visual studio 2008 SP1". Microsoft Corporation.

Pressman, R.S. 2005. "Software Engineering: A Practitioner's Approach". New York: McGraw-Hill. 2002. "Skripsi Pengembangan Perpustakaan Digital Berbasis Web". 